\title{
Margaret McCartney: We should stop fuelling anxiety
}

\author{
Margaret McCartney general practitioner
}

Glasgow

Anxiety is common. We see it every day. Insistent worry, unease, agitation. Palpitations, dry mouth, cold sweat, waking in the night.

Anxiety is a term used so frequently in practice, and often so lightly, that the impact of its gnawing and sprawling nature easily goes unseen. The descriptors "minor" and "self limiting" may be, relatively speaking, true. But an inability to concentrate or relax means losing the pleasure of both work and play.

Heightened concern about small matters means that large matters become insurmountable.

Many people who attend their GP have significant symptoms of anxiety, ${ }^{1}$ and those with chronic diseases carry a heavier burden. ${ }^{2}$ People who attend very frequently often have high levels of symptoms. ${ }^{3}$ A compassionate healthcare system, designed around our patients, would acknowledge this burden's impact and would attempt to mitigate it. But, instead of quelling anxiety, we fuel it.

Try to access healthcare, and posters on pharmacy walls ask passers by to check the yellowness of our urine lest we be dehydrated (despite a lack of evidence that this a useful diagnostic aid ${ }^{4}$ ), or they tell us about the risks of not doing enough exercise. Leaflets ask whether we've accepted our bowel or cervical screening test, which could save our life, and the World Cancer Research Fund invites people to ask themselves whether their diet is "making them cancer attractive."

An inability to concentrate or relax means losing the pleasure of both work and play

Charity groups campaign for disease awareness, but they may end up scaremongering, causing distress and fear rather than improving knowledge.

Researchers' funding may depend on the volume of publicity rather than the quality. The media, doctors, and politicians inform our patients that the NHS is under stress, and many NHS departments have induced a measure of shame among those who are already worried or self blaming, by asserting that these are "inappropriate attendances." It's not in the nature of newspaper headlines to say what we don't need to worry about. But, as the health academic Hans Rosling noted, an unnecessarily pessimistic view of the world does not help to improve it. ${ }^{6}$

Anxiety in patients can get worse when met with an anxious doctor. I've been that doctor many times, fearful of missing a significant diagnosis or of prescribing too little or too much. Anxiety can snowball with more tests that inevitably have some small, questionable abnormality or with more tablets, with side effects. We're anxious that we're not good enough-and we're rarely reassured by data that can't prove that we are.

What would make patients, and doctors, less anxious? My late father in law eschewed all health promotional material in his surgery: instead he offered paintings, comfortable chairs, and attention, with no computer on his desk. Shouldn't we be researching what kind of environments make us more relaxed and less distressed?

We should turn our attention to the causes and effects of our iatrogenic anxieties. Researchers should be given more funding if they achieve suitably sanguine media coverage that rightly reflects uncertainty and nuance. Before release, health promotion materials should be assessed for accuracy and potential anxiety by an independent body and citizen reviewers, some of whom have anxiety disorders themselves. So too should guidelines-which should say what reasonably should not be done, as well as what should.

Competing interests: See www.bmj.com/about-bmj/freelance-contributors/margaretmccartney.

Provenance and peer review: Commissioned; not externally peer reviewed.

1 Walters K, Rait G, Griffin M, Buszewicz M, Nazareth I. Recent trends in the incidence of anxiety diagnoses and symptoms in primary care. PLoS One 2012;7:e41670. 10.1371/journal.pone. 0041670.22870242

2 Remes O, Brayne C, van der Linde R, Lafortune L. A systematic review of reviews on the prevalence of anxiety disorders in adult populations. Brain Behav 2016;6:e00497. 10.1002/brb3.497 27458547

3 Ronalds C, Kapur N, Stone K, Webb S, Tomenson B, Creed F. Determinants of consultation rate in patients with anxiety and depressive disorders in primary care. Fam Pract 2002:19:23-8. 10.1093/fampra/19.1.23 11818346

4 Hooper L, Abdelhamid A, Attreed NJ, etal . Clinical symptoms, signs and tests for identification of impending and current water-loss dehydration in older people. Cochrane Database Syst Rev 2015;4:CD009647.25924806

5 World Cancer Research Fund. Are you making yourself cancer attractive? Take the 5 minute diet test. https://www.wcrf-uk.org/uk/here-help/health-tools/cancer-health-check.

6 Rosling $\mathrm{H}$, Rosling $\mathrm{O}$. How not to be ignorant about the world (TED Talk video). $18 \mathrm{Jan}$ 2018. https://www.gapminder.org/videos/how-not-to-be-ignorant-about-the-world/. 
Published by the BMJ Publishing Group Limited. For permission to use (where not already granted under a licence) please go to http://group.bmj.com/group/rights-licensing/

permissions 